\title{
The Experience and Attitude of Saudi Patients towards Rubber Dam Isolation during Dental Treatments
}

\author{
Basil Yousif Alamassi ${ }^{1}$, Mowaffq Shafi ${ }^{2}$, Ahmed Alenezi ${ }^{2}$, \\ Abdullah Alghamdi ${ }^{2}$, Mohammed Alerredi², \\ Omar Alwazzan ${ }^{2}$ \\ ${ }^{1}$ Lecturer - Department Of Restorative Dentistry- Riyadh Colleges Of Dentistry And Pharmacy \\ ${ }^{2}$ Riyadh Colleges Of Dentistry And Pharmacy
}

\begin{abstract}
:
Objective: The aim of this cross-sectional questionnaire-based study is to determine dental patients' attitudes toward and experiences with rubber dam (RD) isolation during endodontic or operative procedures at Riyadh Colleges of Dentistry and Pharmacy Teaching Hospital.

Materials and Methods: A questionnaire comprising 12 questions was distributed to 120 patients after they were treated using rubber dam isolation by final year students in the clinics of the Riyadh Colleges of Dentistry and Pharmacy. The respondents were asked to complete the questionnaire immediately after the completion of the procedure. The questions were designed to evaluate their attitudes toward and experiences with RD isolation.

Results: Out of 120 questionnaire distributed, 95 (73 male, 22 female) were completed and returned.

The majority of the patients (80\%) had never been treated using RD outside the Riyadh Colleges. A total of $71.6 \%$ of the patients were comfortable during treatment with the $R D$ and $75.8 \%$ indicated preference for treatment with it in the future. Protection from inhaling or swallowing foreign objects was the most commonly mentioned advantage for the patients (93.6\%), while the inability to rinse was the aspect of RD they expressed the most frequent dislike. The only factor that had a statistically significant influence on patients' preference for future treatment with $R D$ was the degree of discomfort they experienced during treatment $(P<0.05)$.

Conclusion: Patients' experiences with and attitudes toward $R D$ isolation during dental treatment were positive, and most of them indicated a preference for treatment with it during future visits. Dentists and dental students should educate their patients briefly about the importance and advantages of RD to achieve high levels of acceptance.
\end{abstract}

Keywords: Rubber dam, isolation, attitude, acceptance

Abbreviation:

RD: Rubber Dam

\section{Introduction}

The use of rubber dam (RD) in endodontics and restorative dentistry is the only available way to guarantee high-quality, safe, efficient, and successful treatment. For a long time, it has been considered the ideal isolation tool, and working with RD during root canal treatment has been considered the standard of care. The $\mathrm{RD}$ offers the practitioner a wide variety of advantages. These include infection control; the prevention of the aspiration of fine instruments; the provision of a dry, clean operating field from which saliva, hemorrhage, and other tissue fluids are isolated; improved visibility and access; and the protection and retraction of soft tissue (lips, cheeks, tongue) that can disrupt operative procedures ${ }^{3,4}$. Clinicians are protected from litigation that would result from aspiration or a patient's swallowing of an endodontic file. Christensen et al. ${ }^{5}$ demonstrated that the use of the RD helped to keep the operating field free of saliva and other contaminants, improving the quality of restorative work and making patients more comfortable. The RD minimized patient conversation and the need for frequent rinsing during treatment, which improved the efficacy of the dental procedure ${ }^{5}$.

Although there is agreement regarding the importance of using $\mathrm{RD}$, their actual usage is low among dental practitioners worldwide ${ }^{6,7,8,9,10}$. The frequently reported reasons for this limited usage of RD during endodontic and operative procedures include patient discomfort, insufficient time and training, cost, prolonged treatment time, and lack of compliance on the patients' part ${ }^{6,7,8}$. Lynch et al stated that these arguments have been mentioned most often by those dentists who themselves do not use $\mathrm{RD}^{9}$. However, according to several studies, the attitudes of patients toward RD were positive, and they showed high levels of acceptance ${ }^{10,11,12,13,14}$. Their positive attitudes toward RD application could be linked to the proper explanation of its benefits, proper application techniques, and short treatment times ${ }^{12}$. In the studies that investigated patients' attitude toward RD, the majority of patients demonstrated high levels of acceptance and preferences for its use during their subsequent appointments and in most of the cases they had positive experience with this isolation tool ${ }^{12,13,14}$. 
Most previous studies were directed at determining dentists' and dental students' attitudes toward RD usage, and little data was available about patients' attitudes toward and experiences with this method of isolation. Hence, our study was directed at investigating patients' attitudes toward and acceptance of RD usage during endodontic and operative procedures by final year dental students at the Riyadh Colleges of Dentistry and Pharmacy.

\section{Materials and Methods}

This descriptive questionnaire-based study was approved by ethical committee of the research Center at Riyadh Colleges of Dentistry and Pharmacy. A closed-ended questionnaire comprising 12 questions was prepared to determine what patients' experiences with RD isolation during dental treatment were. The patients included had just undergone operative or endodontic treatment under RD isolation by final year dental students at the Riyadh Colleges of Dentistry and Pharmacy Teaching Hospital. The questionnaires were distributed to 120 patients, who were asked to complete them immediately then return them to one of the investigators. Each patient received an explanation of the aim of the study and was informed that the data collected would be used confidentially and the completion of the questionnaire would be considered to be consent for participation. Data was collected and descriptive analysis was performed using version 20 of the Statistical Package for the Social Sciences (SPSS) to determine the patients' levels of acceptance and future preference of RD and to correlate these acceptance levels to different factors either associated with the patients (for instance, age or gender) or with the clinical procedure performed (endodontic or operative, degree of discomfort experienced, first experience with RD or having prior experience, and having received an explanation from the treating student or not). The level of significance was selected 0.05 .

\section{Results}

Out of 120 questionnaires distributed to the patients, only 95 (73 male and 22 female) were completed and returned. The ages of the respondents ranged from 18 to 59 years, with a mean age of 36.4 years. The majority of the patients $(n=76)$ had never been treated with RD outside the Riyadh Colleges $(80 \%)$, and their first experience with RD had occurred at the Riyadh Colleges Dental Clinics. Eighty-five patients (89.4\%) stated that they had already received a brief explanation of the benefits of using the RD during operative and endodontic treatment from the treating student before the procedure began. When they were asked about their comfort level during treatment with RD, sixty-eight of the respondents $(71.6 \%)$ indicated that they were comfortable during treatment with RD, while fourteen patients $(14.7 \%)$ stated that they were uncomfortable with it. Only nine patients $(9.5 \%)$ indicated that it was painful for them (Table 1).

Table 1. Respondents' experiences and degree of comfort during treatment with RD

\begin{tabular}{|l|c|c|}
\hline & Frequency (n) & Percentage (\%) \\
\hline Pleasant & 4 & 4.2 \\
\hline Comfortable & 68 & 71.6 \\
\hline Uncomfortable & 14 & 14.7 \\
\hline Painful & 9 & 9.5 \\
\hline
\end{tabular}

Regarding the question of who benefitted more from the use of RD, seventy-one $(74.7 \%)$ of the patients believed that both dentists and patients benefitted from its use, while $12.7 \%$ of them $(n=12)$ considered the of use RD to be beneficial for the dentist only. Moreover,5.2\% $(n=5)$ said that the procedure had no benefits for both (Table 2).

Table 2. Respondents' feelings regarding who benefitted more from RD usage

\begin{tabular}{|l|c|c|}
\hline Benefits from RD Usage & Frequency (n) & Percentage (\%) \\
\hline Dentist and Patient & 71 & $74.7 \%$ \\
\hline Dentist only & 12 & $12.7 \%$ \\
\hline Patient only & 7 & $7.4 \%$ \\
\hline No benefits for either & 5 & $5.2 \%$ \\
\hline
\end{tabular}

For $43.3 \%$ of the patients $(n=41)$, the inability to rinse during the procedure was the most frequent aspect of RD isolation they did not like. The different aspects of RD usage they did not like are presented in table 3 . 
Table 3. Aspects of RD isolation that the participants did not like

\begin{tabular}{|l|c|c|}
\hline $\begin{array}{c}\text { Aspects that participants did not } \\
\text { like }\end{array}$ & Frequency (n) & Percentage (\%) \\
\hline Pain & 9 & 9.5 \\
\hline Inability to rinse & 41 & 43.1 \\
\hline Difficulty breathing & 12 & 12.6 \\
\hline Inability to communicate & 17 & 17.8 \\
\hline Nausea & 5 & 5.2 \\
\hline Length of time of application & 28 & 29.5 \\
\hline Pain in the TMJ & 3 & $3.2 \%$ \\
\hline
\end{tabular}

When questioned about the aspects of RD isolation they considered beneficial, a high percentage of respondents $(93.6 \%)$ indicated that it protects from inhaling or swallowing foreign objects such as the instruments used during the procedure. The aspects of RD isolation toward which they felt positively are summarized in table 4.

Table 4. The advantages and benefits that respondents associated with the use of RD

\begin{tabular}{|l|c|c|}
\hline \multicolumn{1}{|c|}{ The benefits of RD } & Frequency (n) & Percentage (\%) \\
\hline Reduced cross infection & 54 & 56.8 \\
\hline $\begin{array}{l}\text { Protection from inhalation or swallowing of } \\
\text { foreign objects }\end{array}$ & 89 & 93.6 \\
\hline Protection from soft tissue injury & 66 & 69.4 \\
\hline $\begin{array}{l}\text { Prevention of accumulation of water in the } \\
\text { mouth }\end{array}$ & 77 & 76.8 \\
\hline $\begin{array}{l}\text { Protection of soft tissue from irritant } \\
\text { solutions and chemicals }\end{array}$ & 73 & 68.4 \\
\hline $\begin{array}{l}\text { Improved quality of restorations and } \\
\text { endodontic treatment }\end{array}$ & 65 & \\
\hline
\end{tabular}

Regarding their preference for treatment under RD in future visits, seventy-two of the patients (75.8\%) indicated that they would prefer to be treated with it in the future, while twenty three patients $(24.2 \%)$ did not express this preference. Patients' preferences to future RD treatment in relation to age, gender and type of the procedure is presented in table 5.

Table 5. Age, gender and procedure type in relation to patients preference to future treatment under RD.

\begin{tabular}{|c|c|c|c|c|c|}
\hline & & $\mathbf{N}(\%)$ & $\begin{array}{l}\text { Prefer } \\
\text { N }(\%)\end{array}$ & $\begin{array}{l}\text { Don't } \\
\text { prefer } \\
\text { N }(\%)\end{array}$ & $\begin{array}{l}\text { Significance } \\
\text { "P value" }\end{array}$ \\
\hline \multicolumn{6}{|c|}{ Gender } \\
\hline & Male & $73(76.85)$ & $55(75.34)$ & $18(24.66)$ & \multirow{2}{*}{0.29} \\
\hline & Female & $22(23.15)$ & $17(77.27)$ & $5(22.72)$ & \\
\hline \multicolumn{6}{|c|}{ Age groups } \\
\hline & 18-30 & $38(40)$ & $30(78.94)$ & $8(21.06)$ & \multirow{3}{*}{0.09} \\
\hline & $31-44$ & $41(43.15)$ & $31(75.6)$ & $10(24.4)$ & \\
\hline & 45> & $16(16.85)$ & $11(68.75)$ & $5(31.25)$ & \\
\hline \multicolumn{6}{|c|}{ Procedure } \\
\hline & Operative & $51(53.68)$ & 38 (74.5) & $13(25.5)$ & \multirow{2}{*}{0.86} \\
\hline & Endodontic & $44(64.32)$ & 34 (77.3) & $10(22.7)$ & \\
\hline Total & & $95(100)$ & $72(75.8)$ & $23(24.2)$ & \\
\hline
\end{tabular}

Their recommendations to others, such as friends or relatives, regarding treatment with RD isolation are presented in Table 6. Only five patients felt the use of RD is not necessary and they will not recommend its use for others. The only factor that showed a statistically significant influence on patients' future preferences for treatment with RD isolation was the degree of discomfort they experienced $(\mathrm{P}<0.05)$ during treatment with the RD. Other factors, such as age, gender, type of procedure (endodontic or operative), first experience or having prior experience, having received an explanation regarding $\mathrm{RD}$, showed no statistically significant influence on patients' preference for RD usage in the future.

Table 6. Patients' advice to their friends or relatives on the use of RD during dental treatment

\begin{tabular}{|l|c|c|}
\hline \multicolumn{1}{|c|}{ Advice } & Frequency (n) & Percentage (\%) \\
\hline $\begin{array}{l}\text { Highly recommended/ highly } \\
\text { necessary }\end{array}$ & 4 & 4.2 \\
\hline Recommended / necessary & 69 & 72.6 \\
\hline Optional & 17 & 17.9 \\
\hline Not recommended / not necessary & 5 & 5.2 \\
\hline
\end{tabular}




\section{Discussion}

The aim of this study was to investigate patients' attitudes toward and acceptance of RD isolation during operative and endodontic treatment. The bulk of the available data in the literature focuses on dentists' and dental students' attitudes regarding the use of RD, but little data is available about patients' acceptance of and attitudes toward this method of isolation.

The patients included in this study were those treated by the final year dental student in Riyadh Colleges of Dentistry and Pharmacy with either endodontics or operative dental procedure where the use of RD is mandatory is such treatments. Typically, dentists who use RDs do not explain their benefits to their patients. In rare cases, some patients refuse treatment with it due to misconceptions or bad experiences. Currently, dental institutions worldwide teach the use of the RD as an important method of tooth isolation for most dental procedures in adult and child patients. Ideally, dental study should explain to the patient the importance and advantages of RD use before starting the procedure. About ninety percents of the patients in this study said they have received this explanation. The majority of the patients in this study had never experienced treatment under RD outside the Riyadh Colleges Dental Clinics. The results were similar to those of the studies of Kapitan ${ }^{11}$ and Stewardson $^{13}$. This may highlight a general point of low levels of RD usage in Riyadh city. One of the reported barriers to the use of RD by dentists worldwide is patients' discomfort and incompliance ${ }^{4,5}$. The results of our study and many other studies ${ }^{11,12,13}$ showed high levels of acceptance and positive attitudes towards treatment with the RD isolation, especially when they were educated about its importance and benefits during treatment. Based on these findings, we could say that lack of patient compliance is not an acceptable reason for not using this tool of isolation during operative or endodontic procedures.

Patients in this study expressed high levels of acceptance and preference for future treatment under RD. Similar results were evident in other studies that investigated patient attitudes toward RD isolation ${ }^{10,11,12,13,14 .}$ In our study, final year students undertook the application of RD. Given their experience level, it is expected that they would require longer application times than expert practitioners. Furthermore, in most of the cases, the time students spent completing a procedure usually longer than that which dentists would spend completing the same procedure. This may lead us to expect higher levels of acceptance and preference regarding future treatment with RD when more expert dentists perform the procedure. In Stewardson's study ${ }^{13}$, patient preference for future RD usage was lower when students treated the patients, and the author concluded that operator experience improved patient compliance. In Kapitan's study [11], the application time did not influence patients' acceptance. The only factor that was found in this investigation to influence patients' preference for treatment under RD in the future was the level of discomfort they experienced. Those who experienced discomfort or pain during treatment expressed lower preferences for future treatment with RD. Same finding was reported by Kapitan et al. Kapitan et al. ${ }^{11}$.

In our study, gender difference was found to have no statistically significant influence on patients' acceptance of RD. These findings were in agreement with those of Kapitan's study ${ }^{11}$, but in contrast to the finding of Stewardson's ${ }^{13}$ and Vadavathi's ${ }^{12}$ studies, where females had higher levels of acceptance of RD. Age was also found to have no influence on the level of acceptance; this was similar to the findings of Kapitan's ${ }^{11}$ and Vadavathi's ${ }^{12}$ studies but in contrast to the findings of Stewardson's ${ }^{13}$. study where the preference for the $\mathrm{RD}$ increased with the age of the patients. One of the limitations of this study is that it includes only patients whom treated by students. Consequently, it did not evaluate the relation between operator experience and patient acceptance of RD. Hence, it is recommended that investigations be undertaken to determine patients' attitudes toward RD when general dentists or specialists with more clinical skills perform the treatment where the application time and duration of the procedure are expected to be shorter than those associated with students' work.

\section{Conclusion}

Within the limitations of this study, patients generally demonstrated good acceptance levels and positive attitudes toward the use of RD during operative or endodontic procedures done by final year students. The majority of the patients preferred treatment with dental dams in the future and recommended it to their friends or relatives. A short explanation of the importance and benefits of this isolation tool is very important for the improvement of patient acceptance. Hence, any practitioner should carry it out routinely before RD application. The degree of discomfort during treatment with RD isolation was found to have a statistically significant influence on patients' preferences for future treatment with RD.

\section{References}

[1]. American Association of Endodondests: Appropriateness of care and quality assurance guidelines. 3rd ed., 1998 , p16.

[2]. European Society of Endodontology. Quality guidelines for endodontic treatment: consensus report of the European Society of Endodontology. International Endodontic Journal, 2006; 39: 921-930.

[3]. Cochran MA, Miller CH, Sheldrake MA. The efficacy of the rubber dam as a barrier to the spread of microorganisms during dental treatment. J Am Dent Assoc. 1989; 119: 141-144 
[4]. Ahmad IA. Rubber dam usage for endodontic treatment: a review. Int Endod J. 2009; 42(11):963-72.

[5]. Christensen G.J. Using rubber dam to boost quality and quantity of restorative services. J Am Dent Assc. $1994 ; 125$ : $81-82$

[6]. Marshall K, Page J. The use of rubber dam in the UK. A survey. Br Dent J. 1990; 169: 286-291.

[7]. Abraham SB, Rahman B, Istarabadi A, Ali Mahmoud AH, Danielle Q. Attitudes towards use of rubber dam in private practices in the United Arab Emirates. Saudi Endodontic Journal, 2012; 2(3) 142-146

[8]. Jenkins SM, Hayes SJ, Dummer PM. A study of endodontic treatment carried out in dental practice within the UK. Int Endod J. 2001; 34: 16-22.

[9]. Lynch CD, McConnell RJ. Attitudes and use of rubber dam by Irish general dental practitioners. International Endodontic Journal, 2007; 40: 427-32.

[10]. Gergely EJ. Desmond Greer Walker Award. Rubber dam acceptance. Br Dent J. 1989; 167:249-252.

[11]. Kapitan M, Hodacova L, Jagelska J, Kaplan J, Ivancakova R, Sustova Z. The attitude of Czech dental patients to the use of rubber dam. Health Expectations, 2015; 18:1282-1290

[12]. Vedavathi B, Sreenivasa Murthy, Roopa R Nadig, John V George. Patients' Attitude to Rubber Dam: A Short-term Study. World Journal of Dentistry, 2011;2(2):167-168

[13]. Stewardson, McHugh. Patients attitude to Rubber dam. International Endodontic Journal, 2002; 35:812-819

[14]. Jones CM, Reid JS. Patient and operators attitude toward Rubber Dam. Journal of Dentistry for Children, 1988; 55: 452-4 